\title{
FROM CULTURAL PATH TO CULTURAL ROUTE: A VALUE-LED RISK MANAGEMENT METHOD FOR VIA IULIA AUGUSTA IN ALBENGA (ITALY)
}

\author{
L. Van Meerbeek ${ }^{a *}$, L. Barazzetti $^{\mathrm{b}}$, R. Valente ${ }^{\mathrm{b}}$ \\ ${ }^{a}$ Dept. of Engineering, University of Leuven, Kasteelpark Arenberg 1/2200, Leuven, Belgium - \\ lore.vanmeerbeek@student.kuleuven.be \\ ${ }^{\mathrm{b}}$ Department of Architecture, Built environment and Construction engineering (ABC) \\ Politecnico di Milano, Via Ponzio 31, 20133 Milano \\ (luigi.barazzetti, riccardo.valente)@ polimi.it
}

KEY WORDS: Remote sensing, Risk management method, Cultural heritage, Climate change, Value assessment

\begin{abstract}
:
Today, the field of cultural heritage faces many challenges: cultural heritage is always at risk, the large amount of heritage information is often fragmented, climate change impacts cultural heritage and heritage recording can be time-consuming and often results in low accuracy. Four objectives, related to the challenges, were defined during this research work. It proposes a relevant value-led risk management method for cultural heritage, it identifies climate change impact on cultural heritage, it suggests a database lay-out for cultural heritage and demonstrates the potential of remote sensing tools for cultural heritage. The Via Iulia Augusta, a former Roman road in Albenga, was used as case study.
\end{abstract}

\section{INTRODUCTION}

This paper focussed on four challenges in the field of cultural heritage. First, cultural heritage is always at risk. Humaninduced or natural risks have an impact on the state of conservation and the significance of the heritage resource. These impacts can be sudden or part of a very slow process, resulting in reduced values on cultural, social, economic and ecological level. Mitigating these risks is necessary to protect, conserve and transmit cultural heritage to future generations. Secondly, many researches have proved that our climate is changing. These evolutions have worldwide implications in different sectors.

Nevertheless, the link between climate change and cultural heritage is relatively new in research and is in this sense considered as a challenge. Third, the large amount of heritage information is often disjointed, fragmented or restricted. Time, knowledge and resources go lost due to these problems. Finally, the sizes and complexity of the heritage site, the required accuracy and the time span could cause pressure during the heritage recording and documentation. Heritage recording is however an important step in the management process, since it provides valuable information of the primary source, the cultural heritage itself. The produced ground plans, elevations, sections and details are one of the most important primary information sources for every research. Therefore, there is a need for innovative, effective and time-efficient heritage recording techniques in cultural heritage.

The challenges related to risk, climate change, databases and heritage recording resulted in four objectives. The paper aims to propose a value-led risk management method for cultural heritage at risk (Fig. 1), to demonstrate the impact of climate change on cultural heritage, to suggest a database and inventory and to show the potential of remote sensing tools.

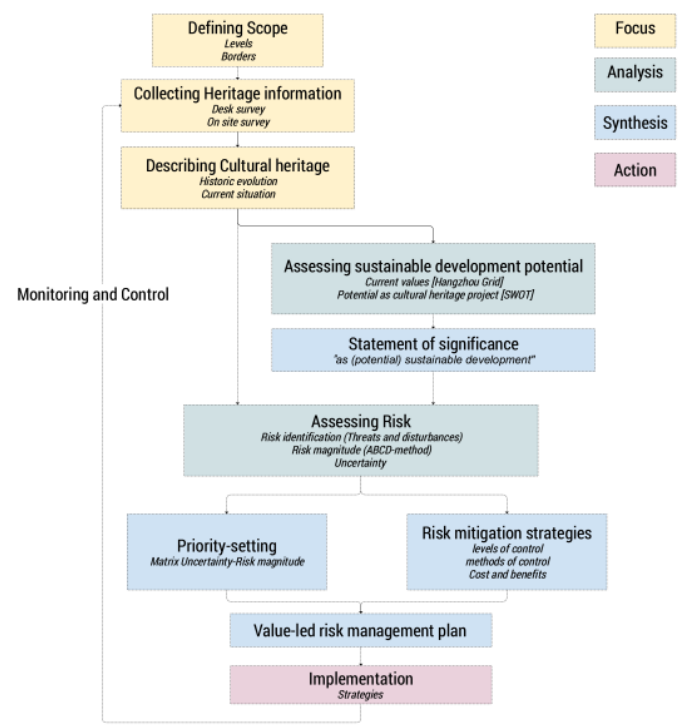

Figure 1. Proposed value-led risk management method

\section{A VALUE-LED RISK MANAGEMENT METHOD FOR CULTURAL HERITAGE. THE VIA IULIA AUGUSTA IN ALBENGA AS CASE STUDY}

\subsection{Defining scope (Focus)}

Identifying the scope and context of a heritage project, defining required heritage information and recording cultural heritage and its wider environment are three required steps before analysis, assessment and management proposals could be formulated (CIPA, 2004; Letellier, 2007). First, the different levels and physical boundaries of the research subject have to

\footnotetext{
* Corresponding author
} 
be defined, in order to have a clear overview on the scale of the project. The scope depends on the amount of time and required detail.

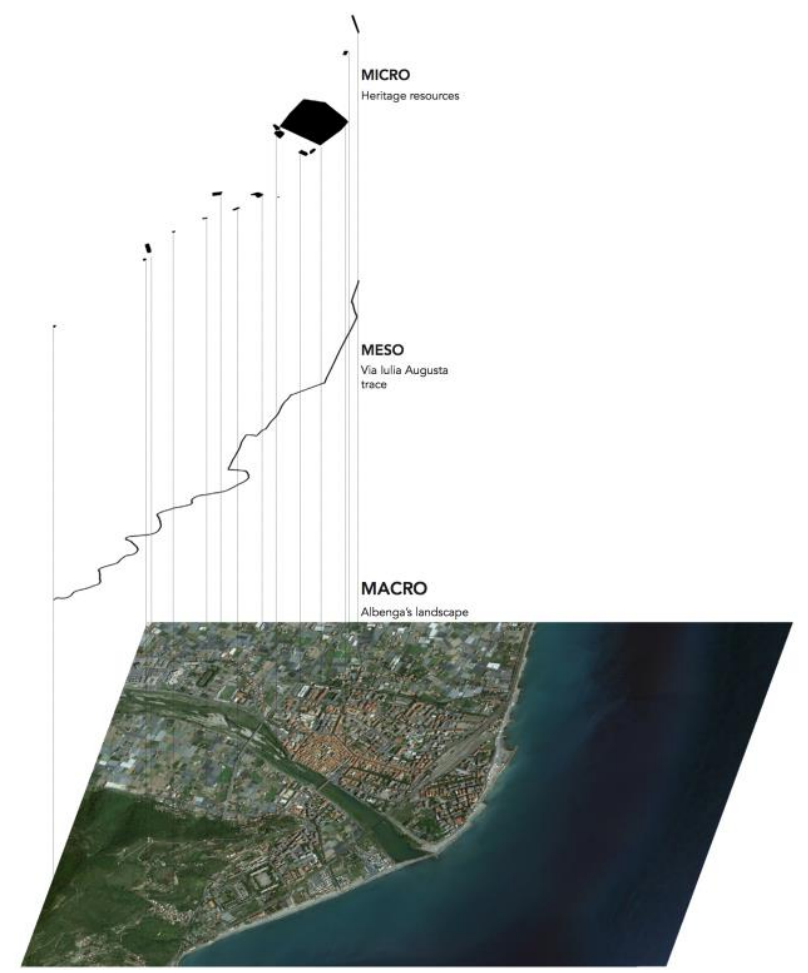

Figure 2. Three research levels for the case study of Albenga

We selected the case study Albenga, situated in Savona, a province of the region Liguria, part of Italy. It is located in the North-West of Italy, close to the French border. Albenga is a relevant research subject to explain the proposed risk management method: Albenga contains a large amount of cultural heritage, such as a former road which connects several heritage resources, and the Ligurian town always has been threatened by water-related problems such as flood.

We defined three research levels in Albenga as scope of the research: the landscape of Albenga (Macro), the Via Iulia Augusta trace (Meso) and the selected heritage elements (Micro) (Fig. 2 and Fig. 3).

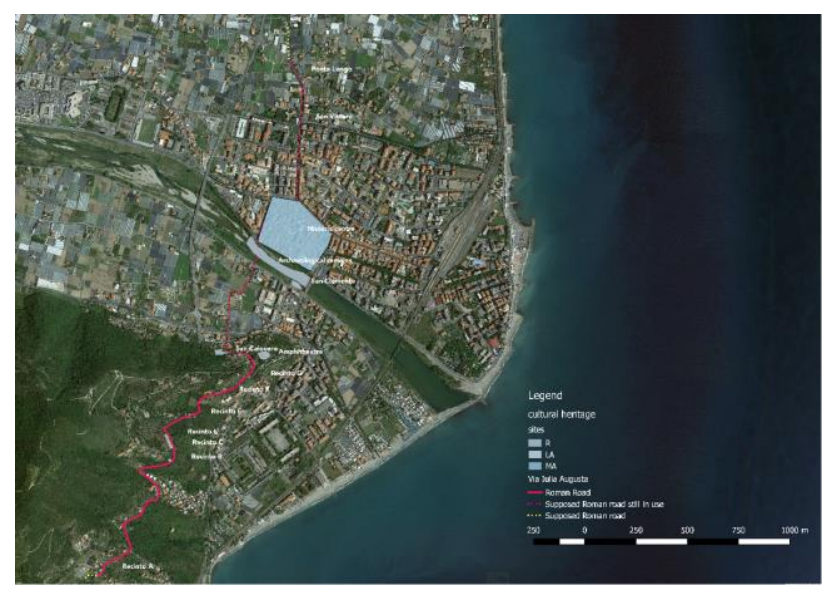

Figure 3. Albenga, the trace of former road Iulia Augusta and its cultural heritage resources

\subsection{Collecting heritage information (focus)}

All the necessary heritage information, directly or indirectly related to the heritage resource, should be gathered via a desk and onsite survey (Styliandis, Patias, and Santana Quintero ,2009). Several remote sensing tools provide heritage information of the primary source, the building and its context (Cuca, 2016).
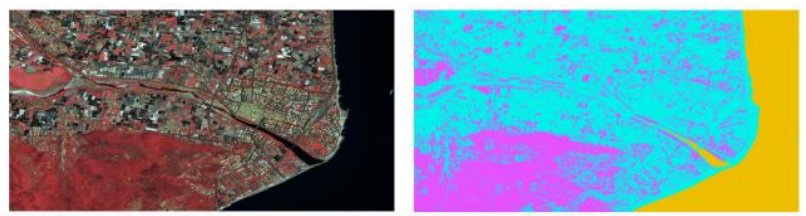

Figure 4. False colour image (left) and classified satellite image (right) gave insight on the land use evolution in Albenga

Different data sources such as cartography, historic documents, climate data, books, scientific papers, satellite imagery and policy documents were gathered through desk survey. This information was sufficient to prepare the onsite visit. The onsite survey proved that heritage sites remain the most important primary source of information. Remote sensing tools such as photo camera, UAV and GPS were relevant tools to gather heritage information (aerial photos and ground control points). Both heritage data retrieved from desk and onsite survey complemented each other. Afterwards, all the obtained data was processed (Fig. 3 and Fig. 4). These information sources are robust pillars for the future description, analysis and assessment of the heritage resources.
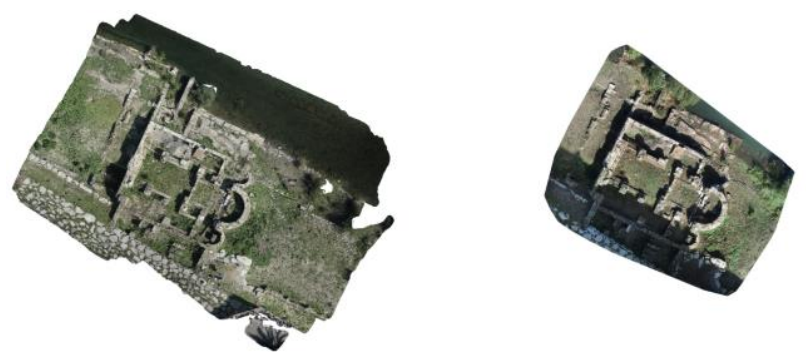

Figure 5. Ortophotos, taken in 2014 and 2016, give insight on the (evolution of the) state of conservation of the cultural heritage resources

\subsection{Describing cultural heritage (Focus)}

Describing the historic evolution, social interactions and economic activities of the cultural heritage and its landscape, reveals important information for further value and risk assessment.

Albenga' landscape is an entity of diverse landscapes, an organically grown, still evolving palimpsest, a connected but at the same time disconnected space and an attractive landscape for cultural, culinary and active tourism, with agriculture as economic asset (Fig. 6).

Secondly, we concluded that the Via Iulia Augusta has the potential to be considered as cultural route, since it has several characteristics related to this concept. The trace physically and culturally connects several cultural heritage resources such as archaeological remains, sites, structures and a historic settlement; it is a combination of different traces; the trace is 
partially recognized as archaeological or even cultural route; different kind of landscapes are visible along this trace; the traces passes different land use zones; and (the space along) the trace is influenced by impacts in the landscape.

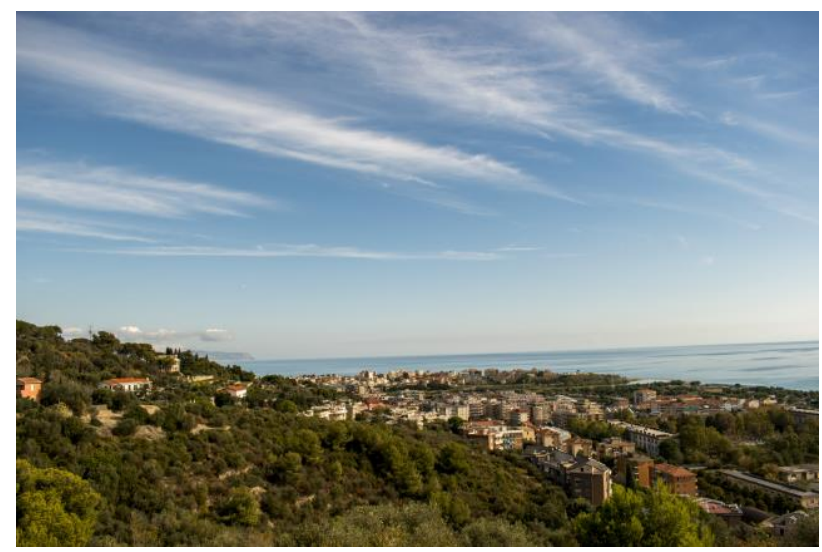

Figure 6. The cultural landscape of Albenga

\subsection{Assessing sustainable development potential (Analysis)}

This step investigates the potential of cultural heritage as vectors for sustainable development in their direct and wider environment. Both value assessment and SWOT analysis were used.

On the one hand, a value assessment helps to identify the current social, cultural, environmental and economic values of the heritage resource(s). There are several kinds of value characterization. This is the result of the multivalence of cultural heritage, because stakeholders all relate differently to cultural heritage. Therefore, a holistic approach is advised. The proposed value assessment combines the Hanghzou declaration and the Nara Document on Authenticity, resulting in the "Hanghzou grid". (Fig. 7) The Hanghzou grid is based on the same principle as the Nara grid, a qualitative value assessment related to the Nara grid that links dimensions (values) to attributes (Van Balen, 2008). We proposed to use the four pillars of sustainability (culture, society, environment and economy), defined in the Hanghzou declaration, as dimensions. The proposed attributes or aspects are the attributes related to the Nara Document on Authenticity (ICOMOS 1994; UNESCO 2015).

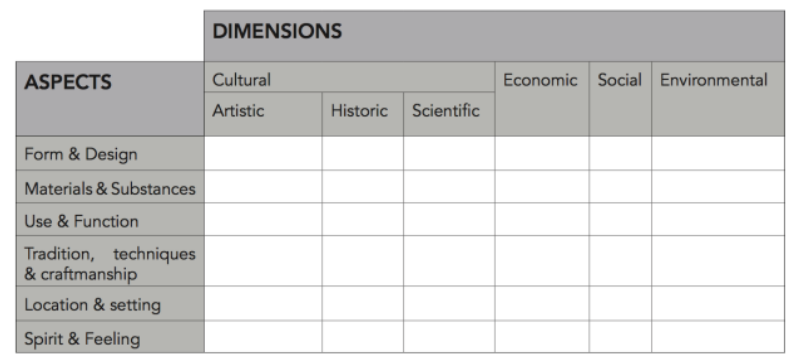

Figure 7. The proposed Hanghzou grid

On the other hand, the SWOT-analysis serves as project evaluation of the cultural heritage. It evaluates the strengths, weaknesses, opportunities and threats of cultural heritage as reconversion project or cultural heritage concept (cultural route, cultural landscape, historic settlement or town...).

The outcome of the two assessments results in a statement of significance. This statement demonstrates the significance of cultural heritage as potential sustainable development project and provides necessary information for the risk impact assessment parameters.

The Hangzhou grid and SWOT-analysis gave insights on the Cultural Route potential of the Via Iulia Augusta in Albenga's landscape. Compared to the Camino de Santiago and the Silk Roads, that are cultural significant on international level, the entity currently has only cultural significance on regional level through its artistic, historic and scientific values. This cultural significance is visible in the attributes of the individual heritage resources and their physical and cultural connection through the trace of Via Iulia Augusta.

In conclusion, the entity of the Via Iulia Augusta in Albenga's landscape has cultural significance on regional level and has the ability to trigger economic, social and environmental significance on local level. Cultural significance is in this sense the basis for further sustainable developments. Therefore, cultural significance, which is mostly visible through the cultural heritage, their physical and cultural connections and the cultural landscape of Albenga, should be preserved or future purposes. Concretely, this implies protection of the cultural heritage resources and the landscape of Albenga.

\subsection{Risk assessment (Analysis)}

Cultural heritage is threatened by several typologies of risk, which makes their future existence vulnerable. To mitigate them, risk assessments are carried out. General risk assessments methods belong to an overall risk management approach, focussing on every kind of risk (human-made or natural; occasional or continuous). We used the risk assessment method of Waller, a strategy originally created to conserve (a group of) museum collections (Waller 1995). In this method, risk assessment contains three steps: risk identification, risk impact assessment and formulation of mitigation strategies. The first step identifies threats and disturbances, caused by agents of deterioration. These threats and disturbances are related to human, development, natural, site management and agricultural impact. The second step analyses different heritage parameters: probability or extent of damage happening, degree of loss of value and integrity and fraction of the assessed area susceptible to the threat. We added "sensitivity to change" as fourth parameter (Burke \& Macdonald 2014). The risk assessment method is in this sense ideal for cultural heritage, since the parameters "loss of value or integrity" and "sensitivity to change" relate to the significance of the cultural heritage resource. Uncertainty on information about risk impact assessment parameters is also assessed.

The outcome is the basis for the formulation of mitigation strategies. These strategies are active or preventive methods of control on the level of the landscape and its policies. Since the method assessed risk from small to large scale, all the information is available to formulate additional strategies on smaller scales of the cultural heritage. The matrix prioritysetting recommends whether risk mitigation, additional research or further cost-benefit/risk mitigation analysis should be carried out (Paolini et al., 2012).

During the risk impact assessment, we focussed on the waterrelated problems that deteriorate Albenga's cultural heritage (Fig. 8). Albenga always has been threatened by flood due to its topography but climate data and climate predictions demonstrate that critical weather events are increasing every year. Other data such as newspaper articles, photos, historic evolution of topography and weather events, risk maps and climate predictions confirm the (moderate to very high) magnitude of other water-related problems such as flood by 
high ground water level, surface runoff water and constant submergence by Centa river.

Based on the combination of risk magnitude for every risk (moderate to very high) and the moderate uncertainty of the risk impact assessment parameters, we recommended several strategies for every risk. For the risk of flood by precipitation and surface runoff, we proposed to prioritize further research, a cost-benefit analysis and a risk mitigation analysis before starting risk mitigation. The risk of flooding by high groundwater level and submergence of water does not require direct action. However, cost-benefit analysis for mitigation and research should be carried out to compare both outcomes and select the most appropriate analysis as future next step. Constant monitoring of the weather and the state of conservation, together with future research on specific damage caused by water-related problems, should also be carried out in the future.

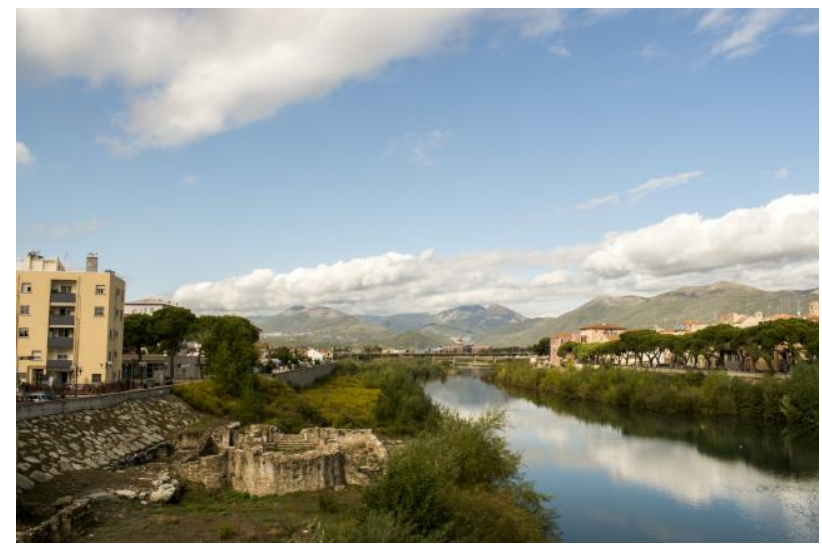

Figure 8. The archaeological site San Clemente in the Centa riverbed, always (partially) flooded

\subsection{Management plan (Synthesis) and Implementation (Action)}

The synthesises "statement of significance", "priority setting" and "risk mitigation strategies" are the basis for the future management plan. The implemented strategies of the management plan, should be monitored and controlled to have an overview of the strategies' impacts on the state of conservation and the significance of the cultural heritage.

\subsection{Geographic Information System as documentation tool for a value-led management method (Control)}

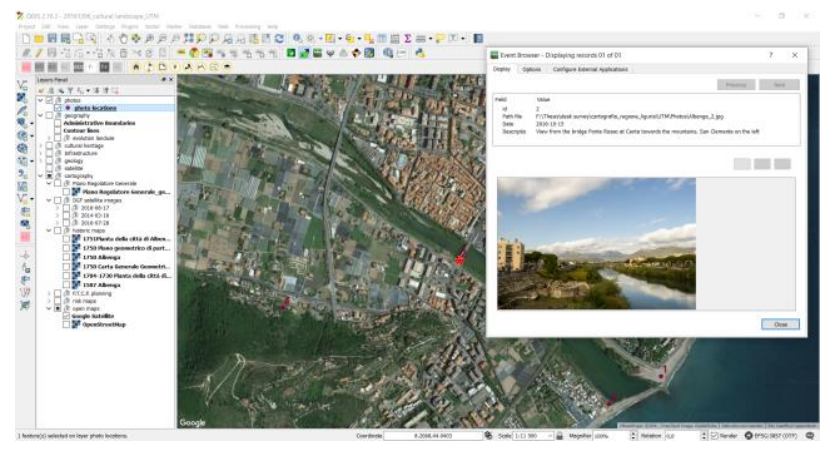

Figure 9. Inventory card of San Clemente, one of the assessed cultural heritage sites
Afterwards, this heritage information should be stored in an inventory. A good inventory is user-friendly, compatible with other inventories and based on international standards. Geographic Information System (GIS) is considered as a practical tool for an inventory. We used QGIS to store current historic maps, photos, policy documents, results of value and risk assessment and other relevant information. Several techniques such as adding shapefiles, georeferencing maps, adding photos, storing excel sheets as attribute tables and creating shapefiles, were used in this phase. The database also gave the opportunity to create a heritage inventory with inventory categories, compatible with international standards and existing inventories (Fig. 9, Fig. 10).

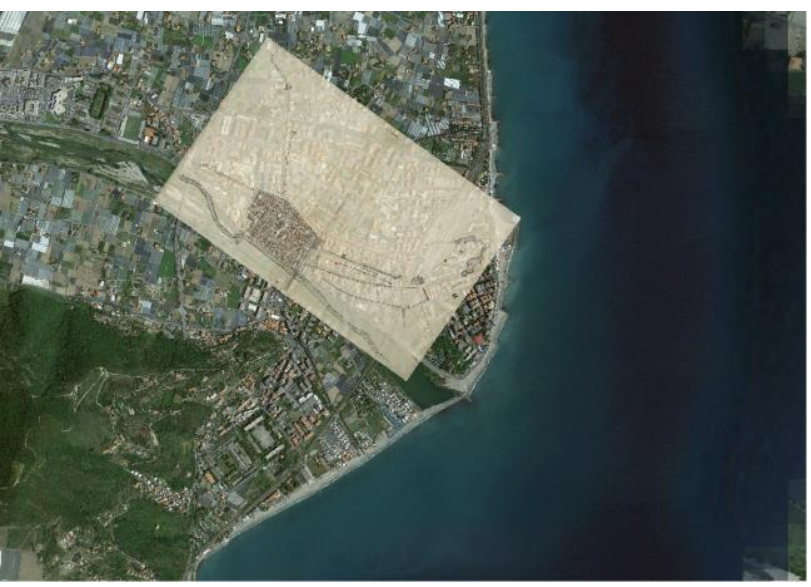

Figure 10. Georeferenced historic map in QGIS

\section{CONCLUSIONS}

The research resulted in several conclusions. First of all, the value-led risk management method showed potential for management of cultural heritage at risk by combining a value and risk assessment. It reveals the reasons to protect and foster the cultural resource and searches for the potential of the site as sustainable development. The landscape-based approach proved to be useful for cultural heritage, from small to large scale. This approach revealed physical, cultural and risk-based interconnections between the heritage resources on different levels. By assuming the risk at the level of the landscape, the risk impact assessment resulted in risk mitigation strategies for cultural heritage resources on the level of the landscape. The proposed strategies are applicable to all the threatened heritage sites in the landscape, resulting in efficient interventions and a more effective risk management. Later on, strategies could be adapted, depending on every site.

Secondly, the research identified the climate change impact on cultural heritage. We used Albenga and its cultural heritage as case study to prove that cultural heritage is currently impacted by the effects of climate change. The water-related risks always have been present in Albenga. However, the amount of critical weather events, triggering the water-related risks, is increasing. Local weather data, photos and information of previous flood, on site surveys and climate predictions demonstrated the current water-related problems and what appears to be an increase of these events. We assessed the risk impact of these climate change effects to the cultural heritage in Albenga. It showed that the significance of the cultural heritage in Albenga is decreasing due to the water-related threats, which become more critical due to global warming. However, constant monitoring of the weather and the state of conservation, and further 
research on the specific damage caused by flood and erosion, should both be carried out in the future, in order to confirm preliminary data on recurrence of negative climate events.

Third, the proposed database for cultural heritage at risk is userfriendly, open-source, free and complementary with existing inventories, international standards and the value-led risk assessment method. The proposed QGIS database fulfilled these aims. The database provided several tools to document different kinds of data, to structure data according to the method's steps, to analyse the case study more efficiently and to be complementary with other existing inventories. Apart from its documentation abilities, QGIS also proved to be a useful and time-efficient visualization and analysation tool during the value-led risk assessment on the level of the landscape. Later on, it could also serve as monitoring tool. By adding recently obtained data, old and current state of conservation can be compared. However, further research should be carried out on the possible advanced use that QGIS offers for the value-led risk management method, such as flood simulation.

Fourth, the research demonstrated the potential of remote sensing techniques in cultural heritage. First, remote sensing tools are effective data gathering tools within the concepts of preventive conservation. Most of the remote sensing tools used during this research such as photo camera, UAV and satellite images are non-destructive techniques. Secondly, aerial orthophotos, created with the use of photogrammetry, gave insight on the state of conservation of heritage sites in different periods. In this sense, remote sensing techniques proved to be useful when monitoring heritage sites. Finally, satellite images are extremely useful for land use classification and its evolution through time (change detection).

\section{ACKNOWLEDGMENTS}

We would like to thank Digital Globe Foundation for the scholarship and the providence of the satellite imagery for the investigation.

\section{REFERENCES}

Burke, S., \& Macdonald, S., 2014. Creativity and conservation: managing significance at the Sydney Opera House. APT Bulletin 45(2-3), pp. 31-37.

CIPA, 2004. Statutes CIPA on heritage documentation.

Cuca, B., 2016b. Remote Sensing for Built Heritage Monitoring : Archaeolandscapes ATHENA project.

Letellier, R., 2007. Recording and information management for the conservation of heritage places: guiding principles. Heritage. Los Angeles, USA, Getty Conservation Institute

ICOMOS., 1994. The Nara Document on Authenticity. Knowledge Creation Diffusion Utilization, 309, pp. 9-12. http://whc.unesco.org/uploads/events/documents/event-8333.pdf (16 Nov. 2016)

Paolini, A., Vafadari, A., Cesaro, G., Santana Quintero, M., Van Balen, K., Vileikis, O., \& Fakhoury, L. (2012). Risk Management At Heritage Sites a Case Study of the Petra World Heritage Site. A Case Study of the Petra World Heritage Site. Amman, Jordan
Styliandis, E., Patias, P., \& Quintero Santana, M. (Eds.), 2009. CIPA Heritage Documentation. Best practices and applications. In: The ISPRS International Archives of Photogrammetry, Remote Sensing and Spatial Information Sciences, Athens, Greece, Vol. XXXVIII

\section{UNESCO, 2015. Hangzhou Declaration. Hangzhou, China}

Van Balen, K., 2008. The Nara Grid: an evaluation scheme based on the Nara Document on Authenticity. APT Bulletin: Journal of Preservation Technology 39(2-3), pp. 39-45.

Waller, R. R., 1995. Risk Management Applied to Preventive Conservation. Storage of Natural History Collections. A Preventive Conservation Approach, 1, pp. 21-27. 